\title{
An Empirical Analysis of the Impacts of the Sharing Economy Platforms on the U.S. Labor Market
}

\author{
Ziru Li \\ Arizona State University \\ ziruli@asu.edu
}

\author{
Yili Hong \\ Arizona State University \\ ykhong1@asu.edu
}

\author{
Zhongju Zhang \\ Arizona State University \\ Zhongju.Zhang@asu.edu
}

\begin{abstract}
Each generation of digital innovation has caused a dramatic change in the way people work. Sharing economy is the latest trend of digital innovation, and it has fundamentally changed the traditional business models. In this paper, we empirically examine the impacts of the sharing economy platforms (specifically, Uber) on the labor market in terms of labor force participation, unemployment rate, supply, and wage of low-skilled workers. Combining a data set of Uber entry time and several microdata sets, we utilize a differencein-differences (DID) method to investigate whether the above measures before and after Uber entry are significantly different across the U.S. metropolitan areas. Our empirical findings show that sharing economy platforms such as Uber significantly decrease the unemployment rate and increase the labor force participation. We also find evidence of a shift in the supply of low skill workers and consequently a higher wage rate for such workers in the traditional industries.
\end{abstract}

\section{Introduction}

Sharing economy platforms leverage information technology (IT) to match the supply of underutilized assets or services (e.g., house, cars, labor) and the demand from individuals who are willing to pay for those assets or services in a real-time manner. Despite the controversy surrounding the sharing economy, its business models have disrupted many traditional industries and gained tremendous popularity over the last few years. One of the potential impacts of the sharing economy platforms is the labor market. According to McKinsey ${ }^{1}$, roughly 162 million people in the USA and the EU work in the sharing economy, equivalent to about $20 \%$ to $30 \%$ of the workforce. Katz and Krueger suggest that the net employment growth in the United States between 2005 and 2015 can be attributed to the rise in alternative work arrangements [24]. In this paper, we propose that there are two main mechanisms through which the sharing economy platforms can shape the labor market: the empowering effect and the substitution effect.

First, the sharing economy is empowering millions of individuals to unlock the value of their time, skills and talents to make money in ways and on a scale not possible before. And the jobs within the sharing economy sectors tend to be flexible in terms of work schedule. Therefore, the sharing economy could provide individuals who cannot work nine-to-five jobs with a viable option to work. Besides, for individuals who cannot find traditional jobs in the competitive labor market, those jobs with low skill requirements and low entry barrier in the sharing economy may serve as viable choices.

Second, besides flexibility, job opportunities in the sharing economy have other advantages over traditional jobs. For example, researchers find that Uber vehicles have higher occupancy rates than conventional cabs [16], a result attributable to Uber's advanced technology and efficient matching algorithm. Additionally, Hall and Krueger found that UberX drivers, the group most comparable to ordinary cab drivers, earned between $\$ 16.89$ and \$18.31 per hour depending on hours worked [23]. Therefore, individuals with low-paying jobs would be more likely to switch jobs and work in the sharing economy. This is what we call the substitution effect: sharing economy has the potential to decrease the labor supply in low-skill jobs. In response to the shift in the labor supply, the companies that provide low-skill jobs would have to increase their wages in order to be competitive in the labor market.

To empirically examine these effects, we collected data from multiple sources. Specifically, we compiled a

\footnotetext{
${ }^{1}$ http://www.mckinsey.com/global-themes/employment-andgrowth/independent-work-choice-necessity-and-the-gigeconomy
} 
unique data set combining Uber entry times (manually collected from a comprehensive search of media reports as well as complemented with data from Uber Research), employment data and position related data from publicly available data sources. We use a natural experiment approach to estimate the effect of Uber entry on the various labor outcomes. Since the time of Uber entry into various urban areas is different, we employ a multi-entry difference-in-differences (DID) method to investigate whether the outcome measures for labor participation, unemployment rate, supply and wage before and after Uber entry are significantly different across the metropolitan areas. We find that Uber's entry into a metropolitan statistical area $(\mathrm{MSA})^{2}$ increases labor participation and decreases unemployment rates for that MSA. In addition, we observed empirical evidence that, after Uber's entry into a MSA, the wage for low-skill jobs increases, a result of the substitution effect. Overall, our study provides evidence of significant impacts of the platform-based sharing economy, in particular Uber's entry, on the labor market.

The rest of the paper is organized as follows. After reviewing relevant literature about the sharing economy and the labor market in Section 2, we develop our hypotheses in Section 3. Section 4 describes in detail the data and our econometric specifications. Section 5 presents our findings as well as additional robustness checks. Section 6 summarizes and provide concluding remarks of the study.

\section{Literature Review}

\subsection{Sharing Economy}

There has been a long stream of research that examine the innovations of digital platforms in the IS literature $[5,20,28]$. The traditional two-sided platforms (such as eBay, Amazon) that facilitate transactions of physical products have slowly given way to the new sharing-based economy in recent years. Sundararajan argues that the sharing-based economy could potentially have significant social and economic implications [30], including the disruption of long-standing industries [27] and displacement of incumbents $[13,21,31,33]$.

There are also studies that have explored the various externality effects of such sharing economy platforms $[18,21,32,33]$. One interesting question is whether these digital platforms are simply introducing digital intermediaries or actually increasing the extent of the gig or contract work. Uber, Airbnb, TaskRabbit, Handy, Freelancer, Upwork, and other platforms are transforming industries by connecting "producers" with customers in new ways. In some cases, this is displacing or threatening existing, often regulated, service providers (such as taxis and hotels). In other cases, it is formalizing previously less organized or locally organized work. Therefore, there is an ongoing debate over whether the sharing economy creates or destroys jobs [25]. To the best of our knowledge, this is one of the first studies that seek to systematically examine the issue of the sharing economy and the labor market.

\subsection{Digital Innovation and Labor Market}

How information technologies are affecting the labor market is a classic research question in the literature. The rapid advancement of technology increases an economy's productive capacity but does not benefit everyone in a society automatically [12]. Technology takes over tasks and destroys job which makes millions of people suffer. In the meantime, proliferation of new technologies can create employment opportunities. Bessen, for instance, demonstrated that the aggregate number of bank tellers increased despite the diffusion of automated teller machines [11]. Similarly, Basker et al. documented that employment per gasoline station increased between 1977 and 1992, even as the share of stations with selfservice pumps expanded from 40 to 80 percent [8]. A growing body of work have examined how local labor markets adjust in response to the arrival of new technologies [2,9]. In particular, some studies [10,17] documented that computer technology has substituted for workers performing routine tasks, leading to downward pressure on employment and suppressed wages for routine jobs. Akerman et al. used variation in broadband availability across areas to examine the causal impact on the labor market outcomes for different types of workers [1]. In this paper, we argue that the sharing-based innovative business models offer workers some unique features (e.g., flexibility, convenience, and control over time and income) that could be both labor substituting (substitution effect) and labor augmenting (empowering effect), highlighting significant implications in the labor market.

\section{Hypothesis Development}

\subsection{Participation and Unemployment}

With information technology, individuals gain new capabilities and channels to participate and express themselves in a networked society. This is called digital empowerment [26]. The sharing economy means

\footnotetext{
${ }^{2}$ https://en.wikipedia.org/wiki/Metropolitan_statistical_area
} 
empowerment for a large number of people who can earn additional income from assets they already own; take control of their own work schedule and income; and do what's best for their family. We expect it could increase labor participation in two ways. First, the sharing economy could encourage individuals to enter the labor force who otherwise would be left out. As discussed earlier, one important benefit the sharing economy provides is work flexibility, which empowers individuals (such as stay-at-home parents, retirees, students, people with disabilities) for whom the conventional routines of nine-to-five jobs aren't an option. Second, the sharing economy provides jobs for individuals who were in the labor force but got laid off. For those individuals, participation in contingent work may be their only option in a tough labor market. Therefore we make the following hypotheses:

Hypothesis 1a: Uber's entry into a MSA increases labor force participation in the MSA.

Hypothesis 1b: Uber's entry into a MSA decreases unemployment rate in the MSA.

\subsection{Labor Supply and Wage}

The emergence and expansion of the sharing economy has fundamentally changed the traditional business models. Many papers have examined the impact of sharing economy on the respective same industry $[7,19,31,33]$.

In contrast to the existing literature, we adopt a cross-industry perspective in this paper. We argue that the sharing economy business models not only disrupt incumbent industry job opportunities, but also have a profound effect on traditional low-skill jobs in the industries. As discussed earlier, jobs in the new sharing economy are flexible, autonomous, and well paid. These relative advantages may attract individuals with lowskill and/or low-paying jobs to switch to jobs in the sharing economy, thus causing a drop of labor supply for the low-skill jobs in traditional industries. In order to stay competitive, the companies that provide low-skill jobs would then need to increase their wages. Hence we make the following hypotheses:

Hypothesis 2a: Uber's entry into a MSA attracts workers with low-skill jobs, thus decreases the total employment of those low-skill jobs in the MSA.

Hypothesis 2b: Uber's entry into a MSA leads to a shortage of labor supply for low-skill workers, thus firms would increase the wage to attract those workers in the MSA.

\section{Data and Methods}

We conduct two parts of analysis to test the hypotheses. Each part draws on different sources of data and different models. We will describe each part in two subsections following the independent variable and the econometric identification.

\subsection{Independent variable}

Since our analysis focuses on one specific sharing economy platform: Uber. So our variable of interest is a proxy for Uber effect. We operationalize the Uber effect to the entry time of Uber into a local area. This data was retrieved manually from major news media. This data contains Uber start date of four different Uber services (UberBlack, UberX, UberXL, and UberSUV) for 157 areas. We use the earliest entry time for any service as the Uber entry time for this area

\subsection{Econometric identification}

We use a natural experiment approach to empirically examine the impact of Uber on the labor market within the United States. This research design offers us an important advantage: Since the time of Uber entry into various urban areas is different, we can use a multi-site entry difference-in-differences (DID) method to investigate whether the labor market measures before and after Uber entry are different across different urban areas [3]. This data structure further enables us to include location and time fixed effects, which effectively control for static heterogeneity across locations, as well as any unobserved temporal trends or shocks (e.g., seasonality). To be more specific, our model specification is given by Equation (1).

$$
\begin{aligned}
& \text { DependentVariable }_{i t} \\
& \qquad \begin{array}{l}
=\alpha+\beta * \text { UberEntry }_{i t} \\
+\lambda * \text { Controls }_{i t}+\theta_{i}+\gamma_{t}+\varepsilon_{i t}
\end{array}
\end{aligned}
$$

In this equation, $i$ represents a metropolitan area, $\mathrm{t}$ is the time period, $\theta_{i}$ is the area fixed effects, $\gamma_{t}$ is the time fixed effects, $\beta$ is the coefficient of Uber entry, $\lambda$ are the coefficients for the control variables, $\varepsilon_{i t}$ is the error term. In this research, we conduct analysis at the metropolitan area level. Uber launches its service mostly in city level, only under a few circumstances, it enters a whole metropolitan area. But we choose the metropolitan area as the unit of analysis based on two reasons: first, Uber launches in one area means its service is legal (enters/launches) in this area, which only affects the pick-up. In this way, Uber drivers can drop someone off wherever they want, but the pick-up must 
be in a legal territory. If an area is "illegal" the company will put a "blackout" or a "block" on it so no riders can request and no drivers can pick up. The other but minor issue is that most dependent variables and control variables included in our models are only available at the metropolitan areas. We use the Uber entry time of the center city ${ }^{3}$ as the entry time for the corresponding metropolitan area.

\subsection{Labor Participation and Unemployment Rate}

We collect labor participation and unemployment rate data from the Local Area Unemployment Statistics (LAUS) program. The LAUS program produces monthly and annual employment, unemployment, and labor force data for census regions and divisions, States, counties, metropolitan areas, and many cities, by place of residence. We use monthly seasonally-adjusted data for MSA considering our research context and question. Since the earliest Uber entry time is 2011 into San Francisco. So we use data from January, 2008 to September, 2016 in order to balance the pre-treatment and post-treatment time periods. Since Uber enters into different cities at different points of time, we cannot find a perfectly balanced time window so that for each area, the number of pre-treatment periods exactly equals to the number of post-treatment periods. When collecting data, we try to make sure the area with earliest entry time has a few years' pre-treatment periods and in this way, we make sure all areas have enough pre-treatment periods and post-treatment periods. Table 1 provides the summary statistics of the data set and the control variables included. The econometric model for testing hypothesis $1 \mathrm{a}$ and $1 \mathrm{~b}$ is shown in Equation (2). $i$ represents a metropolitan area, $\mathrm{t}$ is the time period, $\theta_{i}$ is the area fixed effects, $\gamma_{t}$ is the time fixed effects, $\delta$ is the coefficient of Uber entry, $\lambda$ are the coefficients for the control variables, $\varepsilon_{i t}$ is the error term. For labor participation, we expect $\delta$ is significantly positive. For un-employment rate, we expect $\delta$ is significantly negative.

$$
\begin{gathered}
D V(\text { LAUS })_{i t}=\alpha+\delta * \text { UberEntry }_{i t}+\lambda * \\
\text { Controls }_{i t}+\theta_{i}+\gamma_{t}+\varepsilon_{i t}
\end{gathered}
$$

\subsection{Supply and Wage of Low-Skill Workers}

We check our second hypothesis using data from Occupational Employment Statistics (OES). This program is conducted by Bureau of Labor Statistics (BLS), it produces employment and wage estimates

\footnotetext{
${ }^{3}$ The center city of one metropolitan area is defined by the Census Bureau
}

annually for over 800 occupations. The survey participants are exclusive "employees". This data offers us two advantages: first, OES is employer/payroll survey, which is different from the household survey. For household survey, if a person did any work for pay or profit during the reference period (whether that be wage and salary employment, self-employment, independent contractors, etc.), she is counted as employed. So Uber driver would fall into this category. This is different than the employer/payroll surveys that count only those who were on employer payrolls during the reference period. In that case, an independent contractor like an Uber driver would not be counted. So using the household survey, we can estimate the overall impact of Uber on labor participation and unemployment rate. With the employer/payroll survey, we can investigate the spillover effect of Uber on other traditional low-skill/low-income jobs.

Second, BLS uses the Standard Occupational Classification (SOC) code for all the position related data (include OES). The SOC system is used by Federal statistical agencies to classify workers and jobs into occupational categories for the purpose of collecting, calculating, analyzing, or disseminating data. We can use this code to connect the OES data with the Dictionary of Occupational Titles (DOT) data. The DOT data refers to a publication produced by the United States Department of Labor which helped employers, government officials, and workforce development professionals to define over 13,000 different types of work. The DOT was created by job analysts who visited thousands of US worksites to observe and record the various types of work, and what was involved. The data set provides intensity measures of different skills for occupations. Autor defined three measures: abstract, routine, and manual scores to represent the high, medium and low skill intensity of each job [4]. We adopt the "manual score" for each occupation in this research. Table 2 provides the summary statistics of the variables in this data set.

The econometric model we use for this part is shown as in Equation (3). Specifically, we control for the MSA effect, time effect and MSA specific time trends. For wage, we expect the coefficient of Task Manual Score $\lambda$ to be negative (for a job, the lower skill, the higher manual score and then the lower wage) and the coefficient of the interaction term $\beta$ to be significantly positive. For total employment, we expect $\beta$ to be significantly negative. 
DV $(O E S)_{i t}$

$=\alpha+\delta *$ UberEntry $_{i t}+\lambda *$ TaskManualScore $_{j}$

$+\beta *$ UberEntry $_{i t} *$ TaskManualScore $_{j}+\emptyset *$ Controls $_{i t}$

$+\theta_{i}+\gamma_{t}+\varepsilon_{i t}$

(3)

\begin{tabular}{|c|c|c|c|c|}
\hline Variable & Mean & Std.Dev. & Min & Max \\
\hline Unemployment Rate (\%) & 7.16 & 2.74 & 2.3 & 25.9 \\
\hline Civilian Labor Force & 633,859 & $1,137,815$ & 43,554 & $1.02 \mathrm{e}+07$ \\
\hline GDP & 67,710 & 143,965 & 2,620 & $1,412,183$ \\
\hline Minimum Wage(\$/hour) & 7.51 & 0.65 & 2.65 & 11.5 \\
\hline
\end{tabular}

Table 1. Summary Statistics of LAUS data

\begin{tabular}{|c|c|c|c|c|c|}
\hline Variable & Definition & Mean & Std.Dev. & Min & Max \\
\hline Annual Wage & Mean annual wage & $46,373.69$ & $25,584.49$ & 12,130 & 282,600 \\
\hline Hourly Wage & Mean hourly wage & 22.35 & 12.30 & 5.87 & 135.87 \\
\hline Tot Emp & Total employment & $1,275.54$ & $4,028.82$ & 30 & 230,910 \\
\hline Task Abstract & Task abstract score & 3.03 & 2.34 & 0 & 9 \\
\hline Task Routine & Task routine score & 4.20 & 2.23 & 1.19 & 8.64 \\
\hline Task Manual & Task manual score & 1.12 & 1.30 & 0 & 6.17 \\
\hline
\end{tabular}

Table 2. Definition and Summary Statistics of OES data

\section{Results}

\subsection{Effects on Labor Participation and Unemployment Rate}

5.1.1. Main Results. Table 3 describes the results of model (2). This is the model without control variables. The dependent variable "civilian labor force" is $\log$ transformed. Since the data is seasonally adjusted, so we use monthly fixed effect. We can see that the coefficient of Uber entry is significantly positive for labor force participation and significantly negative for the unemployment rate. And this results are consistent after including the control variables (GDP and minimum wage) as shown in Table 4.

5.1.2. Alternative measure for Uber entry. So far, we have used Uber entry time to proxy for the implementation of Uber service. This approach has limitations. Specifically, after Uber service enters an urban area, it takes time for people to accept and get accustomed to this new service. Therefore, Uber entry may not represent the actual usage rate, and there may be a time lag between Uber entry and its impact on the traffic congestion. In order to alleviate this concern, we use an alternative measure of Uber Entry in metropolitan areas: the number of Uber searches in a metropolitan area on Google Trends. Google Trends is a publicly available web application based on Google Search. It provides us an index of the popularity of the sharing economy platform in a certain geographic region. Google Trends have been previously demonstrated to track economic activities (retail sales, automotive sales, home sales, and travel) in real time [15]. Wu and Brynjolfsson find that Google Trends are better in predicting housing sales and prices than traditional indicators [32].

We used the Google Trends search history of the keyword combination "Uber" + "name of the urban area" to measure the popularity and the usage level of Uber in an urban area. It's reasonable to assume that when a person searches "Uber New York", she is likely to be interested in the Uber service in the New York City. The correlation between Uber entry time and the search volume on Google is positive and significant. There is, however, a potential issue with the search volume on Google Trends. Before Uber actually entered an urban area, the search volume is generally not zero in most urban areas. The non-zero search volume could represent some expectations and curiosity but not the actual Uber usage. We address this problem by multiplying it with the Uber entry dummy variable as a new variable: Uber usage. Table 5 presents the results of our analysis using Uber usage. Once again, we find that our estimation results are robust to this alternative measure.

\subsection{Effects on the Supply and Wage of Low- Skill Workers}

5.2.1. Main Results. Table 6 presents the results of the model (3). Column 3 is for hypothesis $2 \mathrm{a}$. The coefficient of the interaction term for total employment is significantly negative. But for the Uber dummy 
variable, the coefficient is not significant. It means that Uber has significant influence on the employment of low skill jobs. The lower skill the job needs (the higher the manual score), the lower employment, which supports the hypothesis $2 \mathrm{a}$. This effect becomes more intuitive when we plot the marginal effect in figure 1(b). Uber entry increases some jobs' employment (task manual score is around 0), as the manual score increase, as the job becomes the lower skill, Uber entry significantly decreases employment of those jobs. Because of this short of labor supply for traditional low skill jobs. We expect the company has to increase the wage to attract enough labor force (hypothesis $2 \mathrm{~b}$ ), and this hypothesis has been checked according to the results. As shown in the first and second column (annual wage and hourly wage), the coefficients of Uber dummy are not significant, but for interaction terms are significantly positive. The increasing effect becomes obvious after interacting with occupation manual score. It means that Uber entry significantly increases the wage of low skill workers (higher manual score). As shown in figure 1(a) (figure for hourly wage omit for simplicity), the most important signal we can derive is: Uber entry has a significant effect on increasing the wage of lowskill jobs, the lower the skill, the stronger the effect. We also try cluster robust standard errors for the three models. We find that the results are consistent.

\begin{tabular}{|c|c|c|}
\hline Dependent Variables & Civilian Labor Force & Unemployment Rate \\
\hline Uber Entry & $0.023^{* * *}(0.003)$ & $-2.396^{* * *}(0.085)$ \\
\hline Constant & $12.636^{* * *}(0.001)$ & $7.858^{* * *}(0.029)$ \\
\hline Observations & 17220 & 17220 \\
\hline R-squared & 0.117 & 0.305 \\
\hline Area Fixed Effect & Yes & Yes \\
\hline Month Fixed Effect & Yes & Yes \\
\hline Number of MSAs & 164 & 164 \\
\hline
\end{tabular}

Standard errors in parentheses $* \mathrm{p}<0.05, * * \mathrm{p}<0.01, * * * \mathrm{p}<0.001$ (Default in the following tables)

Table 3. Main Results of Model 2 using LAUS data

\begin{tabular}{|c|c|c|}
\hline Dependent Variables & Civilian Labor Force & Unemployment Rate \\
\hline Uber Entry & $0.013^{* * *(0.003)}$ & $-2.065^{* * *(0.116)}$ \\
\hline GDP & $8.05 \mathrm{e}-07 *(3.37 \mathrm{e}-07)$ & $-0.000036(0.000019)$ \\
\hline Minimum Wage & $0.003(0.003)$ & $0.353 *(0.171)$ \\
\hline Constant & $12.570 * * *(0.028)$ & $7.658^{* * *}(1.496)$ \\
\hline Observations & 15648 & 15648 \\
\hline R-square & 0.114 & 0.230 \\
\hline Area fixed effect & Yes & Yes \\
\hline Month fixed effect & Yes & Yes \\
\hline Number of MSAs & 163 & 163 \\
\hline
\end{tabular}

Table 4. Main Results of Model 2 (with control variables) using LAUS data

\begin{tabular}{|c|c|c|}
\hline Dependent Variables & Civilian Labor Force & Unemployment Rate \\
\hline Uber Use & $0.004 * * *(0.001)$ & $-0.650 * * *(0.039)$ \\
\hline GDP & $7.12 \mathrm{e}-07 *(3.24 \mathrm{e}-07)$ & $-0.000027(0.000017)$ \\
\hline Minimum Wage & $0.003(0.003)$ & $0.425 *(0.193)$ \\
\hline Constant & $12.736^{* * *}(0.033)$ & $6.702^{* * *}(1.740)$ \\
\hline Observations & 12480 & 12480 \\
\hline R-square & 0.134 & 0.263 \\
\hline Area fixed effect & Yes & Yes \\
\hline Month fixed effect & Yes & Yes \\
\hline Number of MSAs & 130 & 130 \\
\hline
\end{tabular}

Table 5. Main Results of Model 2 with Alternative Measures 


\begin{tabular}{|c|c|c|c|}
\hline Dependent Variables & Annual Wage & Hourly Wage & Total Employment \\
\hline Uber Entry & $-0.0820(0.0711)$ & $-0.0874(0.0711)$ & $-0.135(0.171)$ \\
\hline Task Manual Score & $-0.0365^{* * *(0.000532)}$ & $-0.0381^{* * *(0.000533)}$ & $-0.00995^{* * *}(0.00155)$ \\
\hline Uber * Task Manual Score & $0.00588^{* * *}(0.00129)$ & $0.00596^{* * *}(0.00129)$ & $-0.0206^{* * *}(0.00374)$ \\
\hline Constant & $10.29 * * *(0.0414)$ & $2.654 * * *(0.0414)$ & $4.798^{*} * *(0.0911)$ \\
\hline Observations & 433,764 & 431,404 & 408,758 \\
\hline R-squared & 0.065 & 0.066 & 0.257 \\
\hline Area specific trend & Yes & Yes & Yes \\
\hline Robust standard error & Yes & Yes & Yes \\
\hline
\end{tabular}

Table 6. Main Results Using OES data

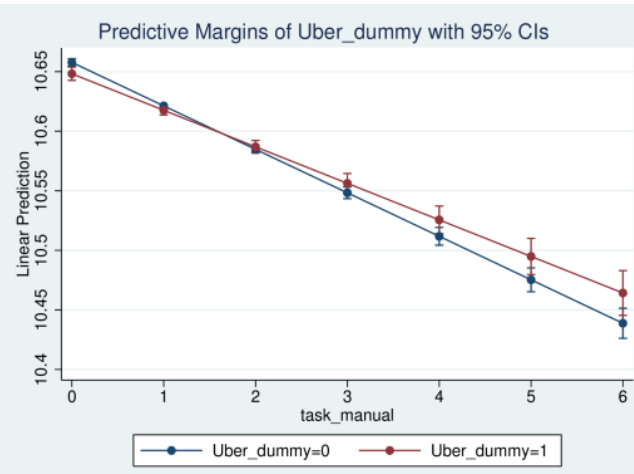

(a) Annual wage as DV

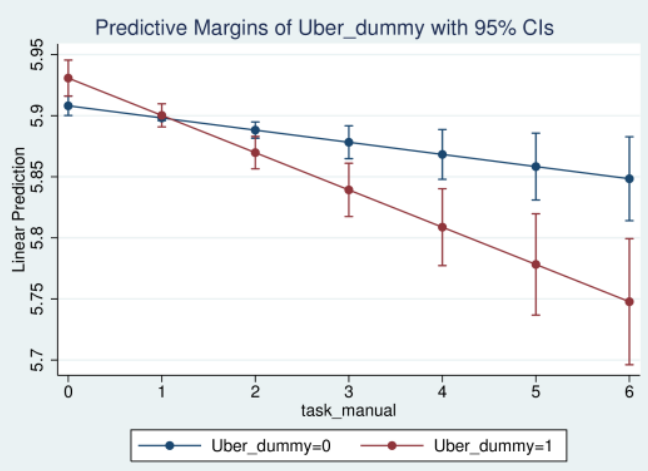

(b) Total Employment as DV

Figure 1. The marginal effect of Uber entry on the marginal effect of task manual score

\begin{tabular}{|c|c|c|c|}
\hline Dependent Variables & Annual Wage & Hourly Wage & Total Employment \\
\hline Uber Use & -0.0129 & $-0.501(1.293)$ & -0.00447 \\
\hline Task Manual Score & $-0.0367 * *(0.000594)$ & $-0.0382 * * *(0.000595)$ & $-0.0113 * * *(0.00174)$ \\
\hline Uber Use * Task Manual Score & $0.00110 * * *(0.000237)$ & $0.00111 * * *(0.000238)$ & $-0.00342 * * *(0.000696)$ \\
\hline Constant & $10.55 * * *(0.0296)$ & $2.911 * * *(0.0297)$ & $5.922 * * *(0.0858)$ \\
\hline Observations & 352,592 & 350,794 & 332,454 \\
\hline R-squared & 0.0273 & 0.0281 & 0.0070 \\
\hline Area specific trend & Yes & Yes & Yes \\
\hline Robust stand error & Yes & Yes & Yes \\
\hline
\end{tabular}

Table 7. Using Google Trend as the proxy for Uber entry

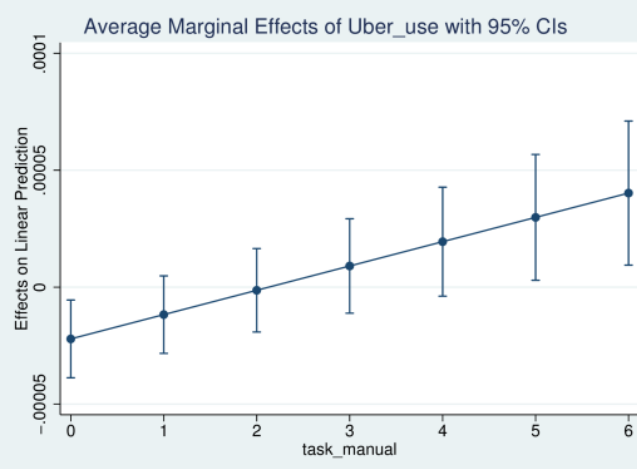

(a) Annual wage as DV

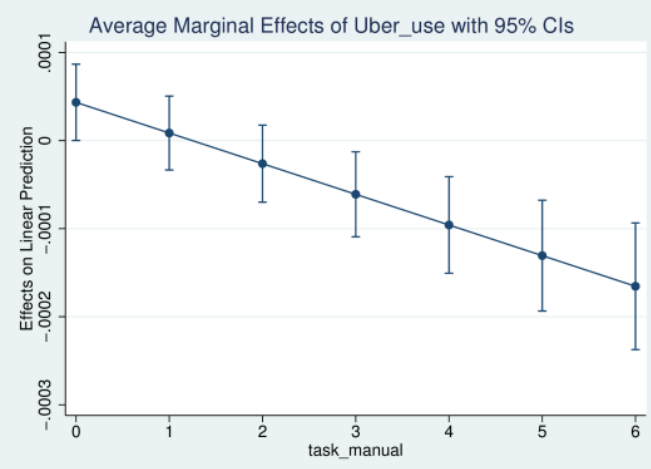

(b) Total employment as DV

Figure 2. The marginal effect of Uber use on the marginal effect of task manual score (alternative measure) 
5.2.2. Alternative measure for Uber entry. As before, we use google trend multiplied by Uber entry dummy to serve as an alternative measure for Uber entry. The estimates are presented in Table 7; the marginal effects are displayed in Figure 2. Overall, our model is consistent using the alternative measures.

\section{Discussion and Conclusion}

Sharing economy is changing the employment landscapes. Rigorous research has been called to quantify the impacts. To the best of our knowledge, this is one of the first studies to systematically analyze the effect of sharing economy on the labor market.

To the degree that much of this work is designed to inform policy, either through a change in the broad understanding of digital phenomena [13,21,22], or by highlighting the differential effects which accrue to different groups [29], our work highlights the need to continue down the important path of providing robust empirical evidence which informs extant debate. Besides, this paper also adds some insights about the impact of digital innovation on the labor market. Sharing economy platforms have experienced a meteoric rise in recent years, and are projected to grow rapidly in the near future. This trend has been the latest and non-negligible revolution. Findings of the how this new form of business model based on digital innovation influences labor participation and workers can be a significant contribution to this research area.

This research also has significant practical implications. It provides some positive evidence on sharing economy platforms, which will either informs the extant debate or informs policy makers. Our rigorous empirical analysis provides additional evidence that sharing economy platforms could actually be part of a solution to unemployment in metropolitan areas. The expansion of sharing economy faces tremendous challenges over the last few years. As discussed earlier, many cities have either banned or forced Uber to close down their business due to various concerns. Our results show that policymakers should also look at the positive side(s) of the sharing economy in order to make informed decisions.

This work is, of course, subject to a number of limitations, which offer potentially fruitful avenues for future work. First, as mentioned above, this paper focus on one sharing economy platform: Uber. Uber has its uniqueness and specialty comparing to other sharing economy platforms. Since the impacts on the labor market are based on the nature and characteristics of the jobs. So our findings may not directly apply to other sharing platforms without further consideration. Additionally, because the sharing economy is a relatively new phenomenon, we are unable to examine the longer term consequences of Uber's entry on the labor market. Future work using more extended panel data is worth to pursue.

\section{References}

[1] Akerman, A., Gaarder, I., and Mogstad, M. The skill complementarity of broadband internet. The Quarterly Journal of Economics 130, 4 (2015), 1781-1824.

[2] Allred, C.R., Fawcett, S.E., Wallin, C., and Magnan, G.M. A Dynamic Collaboration Capability as a Source of Competitive Advantage. Decision Sciences 42, 1 (2011), 129-161.

[3] Angrist, J.D. and Pischke, J.-S. Mostly harmless econometrics: An empiricist's companion. Princeton university press, 2008.

[4] Autor, D.H. Outsourcing at will: The contribution of unjust dismissal doctrine to the growth of employment outsourcing. Journal of labor economics 21, 1 (2003), 1-42.

[5] Bailey, J.P. and Bakos, Y. An exploratory study of the emerging role of electronic intermediaries. International Journal of Electronic Commerce 1, 3 (1997), 7-20.

[6] Bapna, R. and Umyarov, A. Do your online friends make you pay? A randomized field experiment on peer influence in online social networks. Management Science 61, 8 (2015), 1902-1920.

[7] Barro, J. Under pressure from Uber, taxi medallion prices are plummeting. The New York Times, (2014).

[8] Basker, E., Foster, L., and Klimek, S.D. Customer-Labor Substitution: Evidence from Gasoline Stations. (2015).

[9] Beaudry, P., Doms, M., and Lewis, E. Should the personal computer be considered a technological revolution? Evidence from US metropolitan areas. Journal of Political Economy 118, 5 (2010), 988-1036.

[10] Berger, T. and Frey, C.B. Industrial renewal in the 21st century: evidence from US cities. Regional Studies 51, 3 (2017), 404-413.

[11] Bessen, J. Learning by doing: the real connection between innovation, wages, and wealth. Yale University Press, 2015.

[12] Brynjolfsson, E. and McAfee, A. Race against the machine: How the digital revolution is accelerating innovation, driving productivity, and irreversibly transforming employment and the economy. Brynjolfsson and McAfee, 2012.

[13] Burtch, G., Carnahan, S., and Greenwood, B.N. Can You Gig it? An Empirical Examination of the Gig-Economy and Entrepreneurial Activity. An Empirical Examination of the Gig-Economy and Entrepreneurial Activity (March 7, 2016), (2016). 
[14] Chan, J. and Ghose, A. Internet's dirty secret: assessing the impact of online intermediaries on HIV transmission. (2013).

[15] Choi, H. and Varian, H. Predicting the present with Google Trends. Economic Record 88, s1 (2012), 2-9.

[16] Cramer, J. and Krueger, A.B. Disruptive Change in the Taxi Business: The Case of Uber. National Bureau of Economic Research, 2016.

[17] David, H. and Dorn, D. The growth of low-skill service jobs and the polarization of the US labor market. The American Economic Review 103, 5 (2013), 1553-1597.

[18] Edelman, B.G. and Luca, M. Digital discrimination: The case of airbnb. com. (2014).

[19] Fang, B., Ye, Q., and Law, R. Effect of sharing economy on tourism industry employment. Annals of Tourism Research 57, (2016), 264-267.

[20] Forman, C., Ghose, A., and Wiesenfeld, B. Examining the relationship between reviews and sales: The role of reviewer identity disclosure in electronic markets. Information Systems Research 19, 3 (2008), 291-313.

[21] Greenwood, B.N. and Agarwal, R. Matching Platforms and HIV Incidence: An Empirical Investigation of Race, Gender, and Socioeconomic Status. Management Science, (2015).

[22] Greenwood, B.N. and Wattal, S. Show me the way to go home: an empirical investigation of ride sharing and alcohol related motor vehicle homicide. (2015).

[23] Hall, J.V. and Krueger, A.B. An analysis of the labor market for Uber's driver-partners in the United States. National Bureau of Economic Research, 2016.

[24] Katz, L.F. and Krueger, A.B. The Rise and Nature of Alternative Work Arrangements in the United States, 1995 -
2015. NBER. http://scholar. harvard. edu/files/lkatz/files/katz_krueger_cws_v3. pdf, 2016.

[25] Kenney, M. and Zysman, J. The rise of the platform economy. Issues in Science and Technology 32, 3 (2016), 61.

[26] Mäkinen, M. Digital empowerment as a process for enhancing citizens' participation. E-learning and Digital Media 3, 3 (2006), 381-395.

[27] Morse, A. Peer-to-peer crowdfunding: Information and the potential for disruption in consumer lending. Annual Review of Financial Economics 7, (2015), 463-482.

[28] Parker, G. and Alstyne, M.V. Managing platform ecosystems. ICIS 2008 Proceedings, (2008), 53.

[29] Rhue, L. Who Gets Started on Kickstarter? Demographic Variations in Fundraising Success. (2015).

[30] Sundararajan, A. Peer-to-peer businesses and the sharing (collaborative) economy: overview, economic effects and regulatory issues. Written testimony for the hearing titled The Power of Connection: Peer to Peer Businesses, January, (2014).

[31] Wallsten, S. The Competitive Effects of the Sharing Economy: How is Uber Changing Taxis? Technology Policy Institute, 2015.

[32] $\mathrm{Wu}, \mathrm{L}$. and Brynjolfsson, E. The future of prediction: How Google searches foreshadow housing prices and sales. In Economic analysis of the digital economy. University of Chicago Press, 2014, 89-118.

[33] Zervas, G., Proserpio, D., and Byers, J.W. The rise of the sharing economy: Estimating the impact of Airbnb on the hotel industry. Journal of Marketing Research, (2014). 